
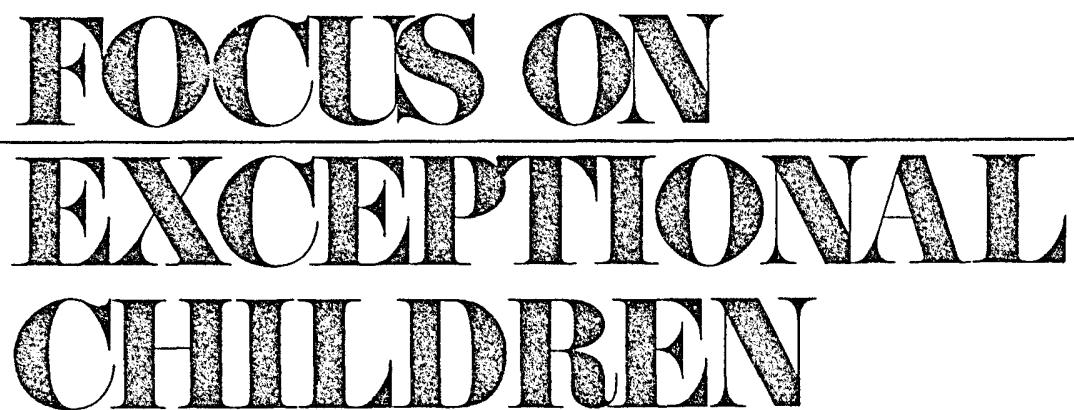

\title{
Learning Disabilities in Adolescent and Adult Populations: Research Implications (Part II)
}

\author{
Gorden R. Alley, Donald D. Deshler, Frances L. Clark, \\ Jean B. Schumaker, and Michael M. Warner
}

Until recently, the amount of data-based literature concerning assessment and remediation of learning disabilities in adolescents and young adults has been slight (e.g., Deshler, 1978a; Wiederholt, 1978). With the inception of the University of Kansas Institute for Research in Learning Disabilities (KU-IRLD), which has targeted the LD adolescent and young adult for study, this literature has expanded greatly. In a previous article in Focus on Exceptional Children (Deshler, Schumaker, Alley, Warner, \& Clark, 1982), the results of the KU-IRLD regarding LD adolescents' achievement, ability, and cognitive processing; the demands of the regular secondary curriculum; and the interventions being developed to help LD students survive the curriculum were reviewed. Some additional findings related to how LD adolescents learn and whether their learning deficits extend to other realms besides the academic area are summarized in the present article.

As stated above, a great paucity of empirical information exists on LD adolescents and young adults, in particular, and underachieving adolescents, in general (Deshler, Warner, Schumaker, \& Alley, in press). As such, most field practices for these adolescents have been based largely on clinical beliefs and nonvalidated models of assessment and instruction. Therefore, the major mission of the KU-IRLD has been to develop effective means of identifying LD populations at the secondary and postsecondary levels and to construct interventions that will have an impact upon school performance and life adjustment.

The KU-IRLD adopted as its primary research strategy the development of a comprehensive epidemiological data base. This data base was created during the initial years of the institute (1977-1979) for the purpose of analyzing data from a variety of sources (parents, teachers, students, administrators, peers, etc.). The goal was to describe both the learner and the settings or conditions under which learning and failure occurred. This research strategy was seen as critical to developing a data-based profile of the older-aged LD individual, as well as a data-based profile of the learning environments for these individuals.

The authors have all been affiliated with the University of Kansas Institute for Research in Learning Disabilities (KU-IRLD), where Dr. Alley is a Research Associate (and Professor, Department of Special Education, University of Kansas), Dr. Deshler is Director, Dr. Clark is formerly of the Institute and now Assistant Professor, Department of Special Education, University of Louisville, Dr. Schumaker is Research Coordinator, and Dr. Warner is Research Scientist. 
After the epidemiology base was in place, the focus shifted to design of intervention procedures. The direction of our intervention research was determined by the epidemiological findings. The majority of our work during the 1980 and 1981 school years was in developing a comprehensive intervention model for LD students in secondary settings. The final phase of the research strategy will be to examine procedures that enhance the generalization of skills across settings and conditions. The research has been conducted in both school and nonschool settings since older-aged LD individuals must be studied in settings that become increasingly important with the passage of time. Therefore, in addition to school settings, we have studied LD individuals in settings such as the Military, Job Corps, employment locales, adult basic education environments, and juvenile courts.

As a result of our research, we have a clearer, but by no means definitive, sense of what the condition of learning disabilities means in adolescent and young adult populations. Hopefully, program decision-making will be enhanced by these data. This article has been organized under four major areas of findings. If $\mathrm{LD}$ individuals are to use newly-learned skills outside of training settings, they must generalize. Their ability to generalize will be explored in the first section. If they are to overcome a history of failure, they must be motivated. Ways to motivate LD adolescents will be reviewed in the second section. Next, in the third section, the finding

FOCUS ON EXCEPTIONAL CHILDREN (ISSN 0015-511X) (USPS 203-360) is published monthly except June, July, and August as a service to teachers, special educators, curriculum specialists, administrators, and those concerned with the special education of exceptional children. This journal is abstracted and indexed in Exceptional Child Education Resources, and is also a vailable in microform from Xerox University Microfilms, Ann Arbor, Michigan. Subscription rates, $\$ 15.00$ per year. Copyright 1983, Love Publishing Company. All rights reserved. Reproduction in whole or part without written permission is prohibited. Printed in the United States of America. Second class postage is paid at Denver, Colorado. POSTMASTER: Send address changes to:

$$
\begin{aligned}
& \text { Love Publishing Company } \\
& \text { Executive and Editorial Office } \\
& 1777 \text { South Bellaire Street } \\
& \text { Denver, Colorado } 80222 \\
& \text { Telephone (303) } 757-2579
\end{aligned}
$$

\section{EDITORIAL BOARD}

Edward L. Meyen University of Kansas
Glenn A. Vergason Georgia State University

Richard J. Whelan University of Kansas Medical Center regarding the relationship of learning disabilities and social skills will be reviewed. Finally, in the fourth section, the question of whether the condition of learning disabilities continues to impact the lives of LD individuals once they leave high school - as young adults -will be explored.

\section{GENERALIZATION}

Generalization of learned behavior across time and settings is one of the most important considerations in developing interventions for learning disabled individuals. Yet, too often it is treated as an afterthought or ignored entirely. If an intervention is to be successful, it must promote the use of the newly-learned skills outside the setting in which, and the conditions under which, those skills were trained. The learner must incorporate the new skills within his/her repertoire to a degree that enables use of the skills long after they were learned -in other classes, in response to other teachers' assignments, in out-of-school settings (e.g., at work), and under differing conditions. To date, little is known about the generalizing ability of learning disabled individuals. Few users of interventions designed for LD individuals have measured whether or not generalization has taken place, nor have they programmed for generalization.

From its inception, one of the three major missions of the KU-IRLD was to investigate the phenomenon of generalization as it relates to the LD adolescent. Studies conducted thus far fall into three categories: generalization across time (skill maintenance); generalization across conditions; and generalization across settings.

\section{LD Adolescents Can Retain Skills Across Relatively Short Periods of Time}

In a number of studies conducted through the KUIRLD, LD adolescents have been trained in various skills. As a continuation of this research, the same adolescents were tested later to determine whether they had retained their newly-acquired skills. Students participating in these investigations had been trained in strategies for gaining information from a textbook chapter (Schumaker, Deshler, Denton, Alley, Clark, \& Warner, 1981), word identification (Lenz, Deshler, Alley, Schumaker, \& Warner, in prep.), social skills (Hazel, Schumaker, \& Sheldon-Wildgen, 1981), and two reading strategies - visual imagery and self-questioning (Clark, Warner, Alley, Deshler, Schumaker, Vetter, \& Nolan, 1981). The period of time between students' mastery of the skill and later testing ranged from two to 
eight weeks. Only in the case of the social skills training were regular reviews of the skills scheduled.

In all cases, the LD students retained use of the skill at or close to their mastery levels. These results indicate that the instructional steps used to teach these skills (Deshler, Alley, Warner, \& Schumaker, 1981) are sufficient to promote short-term maintenance of the skills.

\section{LD Adolescents Can Generalize Skills Across Differing Task Demands (Conditions) Within the Learning Setting}

In several studies, LD students have been asked to apply their skills to materials or situations that were different from the conditions under which they met mastery in the skill. For example, students who mastered the textbook reading strategy in reading materials at their ability level were later asked to use the strategy in grade-level textbooks (Schumaker, et al., 1981). Similar tests were administered to students who mastered the visual imagery strategy and the self-questioning strategy (Clark et al., 1981), and the paraphrasing strategy (Alley, Schumaker, Denton, Warner, \& Deshler, in prep.).

Most of the LD students were able to apply the strategies to the more difficult materials. On comprehension tests over the information covering the more difficult readings, the students who were able to use the strategies received scores comparable to those obtained on tests over the easier readings. The small number of students who could not generalize to the more difficult material exhibited a gap of six or more years between reading level and grade level.

In another study, LD students who learned a paragraph organization strategy also showed generalization across conditions (Moran, Schumaker, \& Vetter, 1981). After learning to write one type of paragraph, an enumerative paragraph, some students showed no generalization while others showed varying degrees of generalization when asked to write a second type of paragraph, a sequential paragraph. By the time they had mastered the second type of paragraph, all students showed considerable generalization when asked to write a third type of paragraph, a compare-and-contrast paragraph. In addition, each time the students were asked to write a type of paragraph they had learned previously, they were assigned a new topic. Their success on new topics demonstrated generalization across paragraph topics.

In several social skills studies (Gorney-Krupsaw, Atwater, Powell, \& Morris, 1981; Hazel, Schumaker, \&
Sheldon-Wildgen, 1981; Whang, Fawcett, \& Mathews, 1981), LD students learned social skills to mastery in the training situation that involved having the students practice the skills while role playing. Later, the students were tested using situations different from the ones used in the practice sessions. For example, a student might have been trained to accept criticism in a practice situation in which his mother gave him criticism about his messy room. Later, the student was tested using a different situation - e.g., a teacher criticizing the student for coming late to class. In all three studies, the LD students showed that they could generalize their use of newly learned social skills across role-playing situations.

Taken together, these studies indicate that LD adolescents can generalize across different task demands once they have mastered a strategy through use of the instructional steps implemented in these studies. The only exceptions were the cases in which students were not able to read the material.

\section{LD Adolescents Exhibit Difficulty Generalizing Across Settings}

In two studies showing LD adolescents' mastery of social skills, the students were observed in other settings to determine whether they applied the skills to those settings. Whang et al. observed the students in their employment settings, and Gorney-Krupsaw et al. observed them in their regular classrooms. Minimal generalization occurred in that students either used a small percentage of the components of a skill or used the entire skill very infrequently. In these studies, it was unclear whether the low generalization noted was due to the few opportunities for using the skill or whether the students really were not generalizing.

In a more recent study (Schumaker \& Ellis, 1982), LD students were trained in social skills outside the resource room and were presented opportunities to use the skills within the resource room. The opportunities were programmed as part of the regular resource room activities, and students were not told in advance about the opportunities.

In one instance, three students learned to ask for more information outside the resource room. On a later day, the students' resource room teacher asked each student to complete a task; the directions were deliberately vague so that the students were unable to complete the task without asking the teacher for more information. Each student was observed to determine if he/she applied the skills learned outside the resource room to this "real-life" situation. 
The results were mixed. All three students in the study showed generalized use of a social skill in at least one "real-life" situation. All of them, however, failed to use a skill in other "real-life" situations. It is unclear what factor(s) might have been responsible in this failure to generalize. Did the students not recognize the situation as one in which they could use the skill? Did the training not emphasize generalization enough? Were the students not motivated to use the particular skill? Was the situation too "emotionally charged" to allow use of the skill?

In a recent project studying LD adolescents' use of writing strategies in their regular classrooms, Schmidt, Deshler, Alley, and Schumaker (in prep.) found that LD high school students did not use the strategies in the regular classroom to the level that they used them in the resource room. In fact, some students failed to use them entirely. Other students showed partial use. These researchers found that generalization training activities were necessary to boost the students' performances in regular classrooms to their performance levels in the resource room. In the generalization activities, the students were made aware of opportunities for strategy use in regular classrooms and were given verbal feedback on their use of the strategy in regular classrooms. If these activities were not successful (as happened with two of the eight students in the study), the researchers found two other kinds of activities useful in promoting generalization: verbal cues from the regular teacher to use the strategy, and self-control procedures (i.e., the students set their own goals, recorded their progress, and reinforced themselves).

\section{Educational Implications}

The studies described above portray a favorable picture for LD individuals' ability to generalize. According to these findings, $\mathrm{LD}$ adolescents can generalize across short time spans and task demands with a minimum of instructional attention devoted to these types of generalization. Whether LD students remember and maintain their use of skills over long time spans is unknown to date. Further research should focus on this question to determine whether instructional time should be devoted to maintenance of these learned skills.

The difficulty students exhibit in generalizing across settings appears to apply to academic as well as social skills. The finding that students did show some generalization across settings in all the studies cited here is a positive sign. Nevertheless, educators should be cautious since LD adolescents' generalization across settings can be inconsistent.
Instructional time may be most effectively devoted to teaching the students how to recognize opportunities for using the skills, giving the students rationales for why they should use the skills, having different people present a variety of "natural" opportunities for using the skills, and giving students feedback about their reactions to these opportunities. Only after an LD student shows that he/she can generalize the use of a skill across time, conditions, and settings can the teacher be assured that the skill is fully incorporated within the student's repertoire and, consequently, that the intervention has had a meaningful impact on the student's life.

\section{MOTIVATION}

Learning disabled students are described in the literature as poorly motivated (e.g., Deshler, 1978b; Henker, Whalen, \& Hinshaw, 1980; Marsh, Gearheart, \& Gearheart, 1978; Wong, 1980) and externally oriented to the causes of behavior (e.g., Hallahan, Gajar, Cohen, \& Tarver, 1978). The major issue involved here is whether LD students' motivational style is determined by a choice to be helpless (e.g., Pearl, Bryan, \& Donahue, 1980 ) or is "paralyzed by" his inability ..." (Siegel, 1974, p. 18). Related to this issue is the question of whether or not LD students can be taught to manage arrangements of learning environments using self-control skills (e.g., Haring \& Bateman, 1977; O'Leary \& Dubey, 1979; Stephens, 1977) in view of their inferior attention to task and inadequate use of study behaviors (Schumaker, Sheldon-Wildgen, \& Sherman, 1980).

Recent studies at the KU-IRLD have focused on each of these issues in an effort to design programming for secondary-level LD adolescents appropriate for their school and post-school needs.

\section{LD Adolescents Are Similar to Their Peers In Their Orientation to the Cause of Their Behavior}

Tollefson, Tracy, Johnsen, Borgers, Buenning, Farmer, and Barke (1980) studied 35 junior-high school LD students' perception of internal and external causality as explanatory of school success and failure. Using the Intellectual Achievement Responsibility Questionnaire (IAR) (Crandall, Katkovsky, \& Crandall, 1965) and the Task Attribution Questionnaire, developed by the investigators for this study, they found that LD adolescents and a group of undifferentiated nonhandicapped adolescents made comparable numbers of internal and external effort attributions. They concluded that LD 
students attributed success on easy tasks to external causality (ease of task); success on moderately difficult tasks to effort; and failure on difficult tasks to their own lack of ability or the difficulty of the task.

Mehring and Alley (in prep.) also used the $I A R$ in applying aptitude-treatment interaction techniques to study the interaction among cognitive style/aptitude variables and a learning strategy. The junior-high $\mathrm{LD}$ students in this study were found to make internal attributions comparable to those of the nonhandicapped group in the Tollefson et al. study. These results were obtained from two school districts differing in respect to size and socioeconomic variables.

Consequently, LD junior-high school students appear not to differ from their nonhandicapped peers in their attributions of the cause of their behavior. This conclusion is generalizable across districts with differing student populations and SES levels.

\section{Goal Setting and Self-Control Systems \\ Can be Effective Strategies for Enhancing LD Adolescents' Cognitive/Academic Performances}

Four intervention studies recently conducted by researchers at the KU-IRLD focused on strategies for enhancing the cognitive/academic performance of LD students. Foster, Dennis, and Maxwell (1981) developed a written, self-instructional package to teach self-control to LD seventh-grade students who demonstrated a low rate of school assignment completion. The package provided information regarding three components: selfrecording, goal selection, and self-administration of reinforcers. Three comprehensive tests were used to determine students' acquisition of the self-management system that was delivered through the instructional packet. Results indicated that LD students could learn selfrecording in one pass through the packet. One pass was not sufficient, however, to teach the concepts of goal selection and self-administration of reinforcers.

Seabaugh and Schumaker (1981a) developed a selfcontrol system for increasing production of completed lessons in programmed self-instructional materials in the basic skill areas of reading, writing, and mathematics. The system was introduced within a series of teacherstudent conferences to secondary-level LD students enrolled in an alternative school. Results showed that LD students were able to set goals in reading, writing, and mathematics and to reach these goals using a behavior contract, self-recording, self-reinforcement and evaluation. The authors also reported some generalization of the training: “. . . when a student finished a sequence of lessons between conferences, and established new goals without adult prompts, the student was exhibiting a type of generalization as a result of training" (p. 27).

In another study, Seabaugh and Schumaker (1981b) studied the effectiveness of parent-teacher conferences and student-teacher conferences on increasing productivity in programmed materials similar to those of the study described above. Conference frequency varied or conferences took place "as needed." The results showed that both types of traditional conferencing situations produced immediate, but minimal, increases in productivity. A great deal of variability was noted after the initial increase, and increases in productivity were neither generalized across skill areas nor maintained across time. This finding suggests that a conference is not sufficient to increase or generalize productivity or to maintain increased production.

Tollefson, Tracy, Johnsen, Buenning, and Farmer (1981) designed a program for teaching LD junior-high school students to set realistic goals. Use of feedback and personal responsibility were stressed as components of the motivational system used. LD students were found to represent a variety of goal-setting patterns. After being provided with effort attribution training, LD students made a slight change in the orientation of their causation for success toward internalization.

In a study that has implications for the areas of reinforcement and self-control, Mellard and Alley (1981) studied junior-high school LD students' performance on a Discrimination Learning Task (DLT) that is sensitive to developmental differences of cognitive development and to the effects of reinforcement conditions. Although LD adolescents were found to demonstrate inferior performance on the DLT, the study also revealed that reinforcement conditions did not differentiate LD students from a nonhandicapped group matched for age and sex. All students demonstrated improvement under the reinforcement condition. In a second experimental session, LD adolescents performed at an inferior level compared to nonhandicapped adolescents under the conditions of reinforcement and response cost. In the post hoc analysis, Mellard and Alley noted that LD and nonhandicapped adolescents were more consistent in their hypothesized problem solution choice and performance choice without reinforcement for correct solutions. Based on these findings, LD junior-high school students appear to require more than reinforcement or reinforcement/cost conditions to improve their cognitive problem solving.

These findings show that goal setting, self-control systems, and reinforcement as used in these studies have equivocal effects on the cognitive/academic performance 
of LD adolescents. Goal setting and self-control systems, in some instances, appear to be able to enhance the performance of LD adolescents.

\section{Educational Implications}

Based on the research of the KU-IRLD, the focus of motivational programming for adolescent LD students should be on allowing them more responsibility for their own behaviors by using self-control or goal-setting management systems. The self-management system that appears to work with LD secondary students includes several integrated elements:

1. Setting realistic, specific weekly goals.

2. Developing plans to meet the goals.

3. Self-recording milestones that progress toward the goal.

4. Self-administering reinforcer(s) when attaining the goal.

5. Conferencing with a staff member once a week to evaluate progress toward goal(s), and setting new goals and plans.

Implementation of the self-management system requires that the teacher or pupil personnel staff member consider the following suggestions of Tollefson, Tracy, Johnsen, Buenning, and Farmer (1981), and others:

1. Setting Realistic, Specific Goals

Setting a time for doing homework.

Answering a certain percentage of study/ vs. Vague Goals test questions correctly.

\section{Setting Incremental Goals}

Answering $70 \%$ of test questions correctly rather than $50 \%$.

3. Developing Plans That Account for Problems

$\ldots$ if the school is closed and I cannot get to the library, use the public library. ...

Spending more time on homework.

Doing better on tests.

\section{vs. Summative Goals}

Answering $100 \%$ of test questions correctly rather than $50 \%$.

vs. Not Accounting for Problems

... get all resources from school library.
4. Setting Goals That are Recordable

... answer all American History study questions by Tuesday at 10:30

p.m. ...

5. Having Students Generate Their Own Reinforcers

. . u upon reaching my weekly goal(s), I will take Julie to a movie on Friday night. If I don't, I'll stay home Friday night.

6. Scheduling a Specific Time for Goal-Setting Session

Teacher: "Let's schedule a specific time to meet each Monday morning to evaluate your progress toward last week's goals and set goals and plans for the next week." "7:45?" "Fine, let's record that time so we don't forget."

\section{SOCIAL SKILLS} and be satisfied with their lives? vs. Not Recordable

... make sure to have studying done. ...

vs. Selecting TeacherGenerated Reinforcers

... upon reaching my weekly goal(s), I will read four chapters in Evergreen.

vs. An "on call" schedule

Teacher: "If you need any help, I'm always here."

For this motivational/management system to function, the LD student must be discontent with his/her present poor performance(s). If the LD student is content with inferior performance, the consequences of this option, along with others, must be explored with the student.

One of the major issues remaining unsettled in the field of learning disabilities concerns the social behavior of learning disabled individuals. Are they socially distinct from their non-learning disabled peers? Does their social behavior constitute a handicap that must be remediated before they can hope to compete successfully

These questions have led to a number of research studies that, until recently, were mostly centered on the elementary-aged student. Results of these studies have 
depicted LD elementary students as less popular than their peers (e.g., Bruininks, 1978; Bryan, 1974; Bryan, 1976) and less socially skilled than their peers (e.g., Bryan \& Wheeler, 1972). Consequently, some authors (e.g., Bryan, 1978) have argued for the inclusion of deficits in social behavior within the definition of learning disabilities, to encourage programming in this area. Nevertheless, no empirical data were available to substantiate whether the social deficits found in elementary LD children were characteristic of LD students or of low-achieving students in general; nor did existing data indicate whether these social deficits obtained at maturity or what effects they might have on the general life functioning of LD individuals. Obviously, answers to these questions are necessary before the programming issue can be settled. Recent studies conducted through the KU-IRLD have shed some light on these issues and suggested some tentative conclusions.

\section{LD Adolescents Are the Lowest of a Group Of Low Participators in Social Activities}

Our epidemiological study of 246 LD, 215 normallyachieving (NA), and 229 low-achieving (LA) adolescents, in which survey data were collected from the youths, their parents, and their teachers (Schumaker, Warner, Deshler, \& Alley, 1980), presents a number of interesting results. First, of a total of 30 variables related to the students' relationships with peers and their involvement in extracurricular activities, only three differentiated LD from LA students: LD students go out less frequently with friends who ask them; LD students ask other students to go somewhere less frequently; and LD students go to sports events less frequently as spectators (Deshler, Schumaker, Alley, Warner, \& Clark, 1981).

The normal achievers were significantly different from both the LD and the LA students on a number of variables. Although the LD and the LA adolescents reported hanging around the neighborhood once a week, the NA students reported doing so once a year. Also, they "hang around" with friends and have friends over to their homes less often. Normally-achieving students were found to participate in an average of 3.7 types of school activities compared to an average of only 1.5 types for both LA and LD students. The NA students spend an average of 8 hours per week in these activities, while LD and LA students spend 2.8 hours per week and 3.6 hours per week, respectively. The NA students stay after school for activities about once a week; the LA and LD students stay after school less than once a month. Finally, the NA adolescents take part in an average of 1.4 out-of-school activities, while the average for LD and LA students is .8 out-of-school activities.

In spite of these differences, the three groups of students did not differ on a number of other variables. They receive phone calls from friends equally often, call friends as often, and report equal numbers of close friends. Teachers reported that they interact with peers equally well.

Thus, on the one hand, we can conclude that LD adolescents are not social isolates. They have friends and engage in activities with their friends. They do not appear to be socially distinct from others who are having difficulty in school. Consequently, social deficits may not be related to LD per se but, rather, to low achievement in general. On the other hand, LD adolescents appear to be members of a low social participating group. Their social activities are not of the organized type. Furthermore, they are the lowest participators among this low participatory group.

\section{LD Adolescents Have Been Observed \\ To Interact With Peers at Rates Equal \\ To Those of Their Non-LD Peers}

The study described above included information on how the youths were behaving in the social arena. To determine how closely this information reflected their actual behavior, Schumaker, Sheldon-Wildgen, and Sherman (1982) observed LD junior-high school students and normally-achieving students in their classrooms. Among the behaviors measured were the numbers of times students: (a) initiated interactions with peers, (b) were the targets of peer initiations, (c) responded to peer initiations, and (d) engaged in conversations with peers. The numbers of different peers with whom each student interacted were also measured.

No significant differences were noted between the LD and normally-achieving groups on any of these measures. In fact, as the LD students matured, they appeared to engage in more interactions with peers than did the nonLD students, who spent more of their time in class working. Again, it can be concluded that LD adolescents are not social isolates; they interact with peers at rates equivalent to those of non-LD peers.

\section{The Quality of LD Adolescents' Social Interactions Is Similar to That of Non-LD Youths With Social Problems}

Although the observational data reported above focused on the rate of LD students' social interactions, no information was provided on the quality of their 
interactions. A study by Hazel, Schumaker, and SheldonWildgen (1981) compared the quality of interactions of eight LD students and two groups of non-LD students. The non-LD students, in this case, were a group of eight juvenile delinquents and a group of eight adolescents who were attending an alternative high school. Both comparison groups were considered by the authors to have been referred to their respective agency (i.e., the group social skills training program and the alternative school) for social problems.

A social skills assessment device (Hazel, Schumaker, Sherman, Sheldon-Wildgen, 1981) was used to test the adolescents' ability to perform six basic social skills: giving positive feedback, giving negative feedback, accepting negative feedback, resisting peer pressure, negotiating conflict situations, and solving social problems. Each youth's skills were tested in a series of six short role-playing situations. As the youth performed the skill, he/ she was observed to determine what percentage of the crucial steps of the skill were performed satisfactorily. Results showed that the three groups of students performed the skills similarly.

Later, a different group of 119 LD high school students from two school districts were tested using the same assessment device, this time testing eight social skills (Schumaker, Hazel, Sherman, \& Sheldon, 1982). Their data were compared to the test results of a group of 57 juvenile delinquents (JD) specifically referred by their probation officers for social skills training. The average LD student profile across six of the skills was similar to, but slightly higher than, the average JD profile across these six skills. On two of the skills (giving negative feedback and conversation) the JD youths performed slightly better than the LD youths. Ten or fewer percentage points of difference were found between the means of the LD and JD groups on any given skill.

These data also indicate that social skills deficits are not characteristic of every LD student, just as they are not characteristic of every juvenile delinquent. Some LD students performed as high as $76 \%$ of the skill steps required by the test. When a subsample of 25 females and 25 males was randomly selected from each group (JD and LD) and their performances compared, no statistical differences were found between the groups on seven of the eight skills. The LD students performed significantly higher than the JD group on only one skill: resisting peer pressure.

These data suggest that LD students as a group do not perform better than juvenile delinquents and other students with social problems on certain basic skills. Some individual LD students in our samples, however, were highly skilled in social interactions.

\section{The Quality of LD Adolescents' Social Interactions Differs From That of Normal Achievers In Specific Social Situations}

The same researchers (Schumaker, Hazel, Sherman, \& Sheldon, 1982) compared the social skills performance of the $119 \mathrm{LD}$ high school students to the performance of 60 normal achievers. The normal achievers were members of the high school band and were required to be passing all courses in school to participate in band activities. On the test of eight social skills in role-playing situations, the average LD student performed $12 \%$ fewer social skills steps than the normal achiever. Average differences between the two groups ranged between $6 \%$ and $18 \%$ on particular social skills, with the normal achievers performing higher than the LD students in every case. When a subsample of 25 females and 25 males was selected out of each group and their performances compared statistically, the non-LD students' performances were found to be significantly higher than the LD students on seven of the eight skills. On the skill of following instructions, no significant difference emerged between the groups.

Another similar device was used in comparing the quality of these two groups' social interactions in occupational situations (Mathews, Whang, \& Fawcett, 1980). Students individually performed social skills in a series of 10 role-playing situations. The students' performance was observed to determine what percentage of the important steps was performed well. Both the LD and the non-LD youths were found to perform poorly in the role-playing situations. The LD students performed significantly worse than the non-LD students on the following four skills: participating in a job interview, accepting criticism from an employer, providing constructive criticism to a co-worker, and explaining a problem to a supervisor. All four of these skills are important in obtaining and maintaining a job. Consequently, when competing with non-LD youths for a job, LD adolescents' job interview performance is more likely to disqualify them for the job even if all other variables are equal.

In a study designed to investigate the social communications of LD and normally-achieving adolescents, Banikowski and Alley (1981) found no differences between the two populations on either quantitative or qualitative measures of interactions. No differences between the two groups may be attributed to the conditions under which the data were collected; that is, students were asked to interact with each other under "contrived," highly-structured conditions that may have resulted in different communication patterns. On the 
other hand, since the level of communication observed in each group was not as sophisticated as hypothesized, these results may be indicative of the unique interaction patterns that typify communications among junior-high school students. Regardless of explanation, this study underscores the complex task of understanding the social interactions of LD students.

\section{Social Problems of LD Individuals Past High School}

Two recent studies have yielded information regarding the lives of LD individuals after they leave high school. White, Schumaker, Warner, Alley, and Deshler (1980) reported a comparison of matched $\mathrm{LD}$ and non-LD (NLD) individuals who had been out of school for a period of between one and seven years. They found the two samples to be similar in many ways. These similarities included the number of close friends both groups reported having. In terms of their contacts with parents and relatives, however, LD young adults were significantly less satisfied than the NLD young adults. Also, the LD young adults reported that they engaged in recreational and social activities significantly less often than did the NLD group. The NLD group reported belonging to significantly more community clubs and groups than did the LD group. Although the difference was not significant, the NLD group reported having more friends with whom they could go places or share activities than did the LD group.

In a second study, Vetter, Deshler, Alley, Schumaker, Warner, and Alley (in prep.) found that significantly more LD young adults reported dating problems than did NLD young adults. The same difference was noted in reports of how they occupied their free time. Significantly more LD young adults reported watching television in their free time.

Results from these two studies indicate that the social problems exhibited by LD adolescents continue to have an impact on their later lives. The activities in which they choose to engage and the number of friends with whom they share these activities are influenced by their social problems.

\section{LD Adolescents Can Learn to Use Complex Social Skills And Apply These in Novel Role-Playing Situations}

Based on results of the studies reported above, LD adolescents clearly exhibit some social skills deficits, presumably caused by their failure to learn social skills within the naturally-occurring social environment. To investigate whether or not LD adolescents would have difficulty learning social skills in a program specifically designed to teach these skills, three separate groups of researchers within the KU-IRLD have used basically the same procedures to teach different social skills to LD adolescents. Whang et al. (1981) taught occupational social skills; Gorney-Krupsaw et al. (1981) taught social skills for interacting with teachers; and Hazel, Schumaker, \& Sheldon-Wildgen (1981) taught the six general social skills described above.

All studies arrived at the same conclusion: LD adolescents learned the social skills very quickly. Furthermore, they were able to apply the skills (generalize) to new role-playing situations.

\section{LD Adolescents May Have Difficulty Applying Newly-Learned Social Skills Within the Natural Environment}

Both Whang et al. and Gorney-Krupsaw et al. reported testing the students' use of the skills in the natural environment after the students had met criterion in training. Whang et al. measured the skill usage at an employment setting, while Gorney-Krupsaw et al. measured it within the regular classroom. Both groups of researchers found little transfer of the social skills. This was not particularly surprising since neither group of researchers had specifically designed their training to ensure generalization, nor had they programmed opportunities for use of the skills in the natural environment.

Schumaker and Ellis (1982) extended this work by injecting opportunities within the natural environment for specific kinds of social interactions. Teachers and other students participated in presenting opportunities within the naturally-occurring classroom environment to three project subjects before and after training on three or four social skills. Subjects were not aware of the teachers' and other students' roles in participating in the tests.

The researchers found that sometimes the LD students generalized to the natural environment and sometimes they did not. No particular pattern for predicting generalization emerged. They also found that the students' performance in novel role-playing tests did not necessarily reflect how they would perform in the natural environment. They might perform poorly in a role-play test but do well in the classroom on the same skill. They might do well on a role-play test and then do poorly in the classroom on the same skill. Schumaker and Ellis 
concluded that generalization training, including use of newly-learned skills in the natural environment, should be a part of any social skills training program for LD adolescents.

\section{Educational Implications}

Results of our social skills studies to date indicate that social skills deficits cannot be classified as a characteristic solely associated with learning disabilities. Other nonlearning disabled youths exhibit similar social deficits. Nevertheless, the social deficits of some LD individuals are evident and appear to have an impact on their lives, even after they leave high school. These findings point to the need for social skills curricula and social skills programming for these individuals. Practical assessment devices, then, are needed to identify social skills deficits of individuals.

Social skills programming need not be limited to LD individuals, but should include anyone experiencing difficulties in the social realm. The benefits of this type of programming are promising since LD adolescents seem not to exhibit difficulty learning social skills. Care should be taken, however, to emphasize generalization to the natural environment. LD students may have to work on generalization more than other students, although this assumption has not yet been specifically validated. Only with social skill assessment and programming can LD individuals hope to compete within the social realm, compensate for academic deficits with social finesse, and live full and satisfying lives.

\section{LEARNING DISABILITIES}

\section{AMONG YOUNG ADULTS}

All students who graduate from high school experience feelings of self-doubt, insecurity, and anxiety (Siegel, 1974). These feelings are common to most persons who reach a crucial developmental juncture. To assist a person in coping with these feelings, accompanying feelings of hope and success usually intermingle with the less positive emotions.

Unfortunately, low-achieving students who drop out of school or somehow manage to graduate, arrive at this crucial juncture without a success history or the support of hope from their classmates. For example:

... it was always the others who were chosen "most likely to succeed," became the school athletes, got elected to student councils and office, had dates, belonged to cliques and clubs, had places to go and things to do, and were recognized by their teachers as having academic abilities and leadership qualities. (Siegel, 1974, p. 95)

Learning disabled students are among this group of low achievers. As such, they evaluate their options of further training, occupational placement, and daily living environments with little hope and anticipation of success.
Limited empirical data exist to confirm Siegel's picture of the LD young adult, primarily for two reasons. First, the category of learning disabilities within the field of special education has existed little more than a decade. Thus, students who graduated in 1981 may not have received LD services because of inaccessibility to trained LD teachers or trained personnel who could identify LD individuals. Furthermore, secondary-school programming for LD students existed in only a few districts prior to 1976. Second, the support agency for handicapped adults in the Rehabilitative Services Administration (RSA), which includes state vocational rehabilitation (VR) agencies, did not have an eligibility classification for LD persons until 1980. Thus, LD programming at the secondary level and vocational rehabilitation programming are still in the earliest stages of development.

Existing follow-up studies of LD adults (e.g., Schwartz, Gilroy, \& Lynn, 1976; Lehtinen \& Tuomisto, 1977; Kirk, Kliebhan, \& Lerner, 1978; Blalock, 1981) have not yielded consistent results on the long-term effects of learning disabilities in adults. This ambiguity is a result, in large part, of the variance in the population definitions and the procedures used for selecting the sample populations. Some study groups were drawn from client populations of university-based clinics (Blalock, 1981); others were sampled from the population of school failures (Hardy, 1968; Lehtinen \& Tuomisto, 1977). In addition, researchers used a wide variety of diagnostic procedures, identification procedures and methods, and criteria more appropriate for classifying learning disabilities in children than in adults (Blalock, 1981). Furthermore, most adult studies have measured occupational achievement and social adjustment in a restrictive sense and, thus, failed to measure the broader array of factors known to be indicative of personal, social, and vocational success.

Recent studies conducted by the KU-IRLD (Alley, Brownlee, Deshler, \& White, 1982; Harnden, Meyen, Alley, \& Deshler, 1980; White et al., 1980; Harnden, Alley, \& Deshler, in prep.) provide empirically-based conclusions that more clearly delineate the issues of learning disabilities among adults. The conclusions and a brief description of the data supporting each conclusion are briefly discussed below.

\section{Learning Disabilities Can Be Found}

\section{Among Young Adults in Several Training Settings}

In a recent pilot study (Harnden et al., 1980) $29.2 \%$ of LD high school students were found to qualify for enlistment in the Army based on performance on the Armed Services Vocational Aptitude Battery (ASVAB), Form 5. Since these results indicated that some LD 
individuals might qualify for service in the Army, Harnden et al. (in prep.) also studied the prevalence of learning disabilities among U.S. Army enlistees. Their sample included 514 enlistees in basic infantry training. The identification battery they used consisted of (a) the Self-Rating Checklist (SRSC) (Alley, Deshler, \& Warner, 1982), which was modified for administration to young adults in the Armed Forces; (b) Raven's Progressive Matrices, Standard Form (Raven, 1956); and (c) the Writing Cluster of the Woodcock-Johnson Psycho-Educational Battery (Woodcock \& Johnson, 1977).

This battery was administered to all enlistees, and those who met the LD criteria (4.5\%) were classified as LD for purposes of the study. The remaining enlistees were classified as non-LD. When the LD enlistees' performances in basic training were compared with the performances of non-LD enlistees, the LD group's performances were statistically comparable to the non-LD group in every area measured except for the "Run, Dodge, Jump" activity of which their mean score was statistically inferior to that of the non-LD group.

In another study designed to identify learning disabilities among young adults, Alley, Brownlee, Deshler, \& White (1982) selected a sample of 560 Job Corp members as they were being oriented to the training center. The investigators used the same battery as was used with the U.S. Army recruits. The cutoff points of the identification measures used, however, were arbitrarily modified to account for the demographic profile of the Corps members. Using these three criteria, $21 \%$ of the Corps members were categorized as LD. A fourth criterion - a grade equivalent greater than third grade, fifth month on the reading subtest of the Stanford Achievement Test was added. When this fourth criterion was added to the preceding three criteria, $9.0 \%$ of the Corps members were identified as LD.

These two studies of the prevalence of learning disabilities in two adult training centers must be viewed as only initial probes. Nevertheless, they do support the conclusion that LD persons are most likely found in various adult settings.

\section{LD Young Adults Encounter Difficulties When Coping with Daily Living}

\section{And Career-Vocational Demands and Personal Goals}

An investigation conducted by White et al. (1980) was designed to determine the current status of 47 young adults identified as LD during their school career, as compared to that of 59 young adults not identified as LD. The subjects had been out of school from one to seven years. Several significant differences were reported between the groups. In the area of vocational adjustment, LD students were found to be holding jobs with less social status and to be less satisfied with their employment situations when compared to their non-LD peers. Socially, the groups differed mainly with respect to the degree of involvement in recreational activities and social organizations and degrees of satisfaction with parental contacts. More prescription drugs and a greater number of arrests and criminal convictions were reported for LD young adults than for non-LD young adults, although the differences were not statistically significant. In addition, LD young adults were found to be less satisfied with their school experiences, to have lower aspirations for future education and training, and to entertain fewer educational plans. LD young adults also reported receiving less support from parents and relatives and more from professional counselors.

In spite of these differences, the groups were similar in a number of other areas. Individuals from both categories were holding approximately the same number of full-time jobs, were earning about the same salaries, and were spending about the same amount of time being unemployed. Both groups had a number of friends; more persons in both groups lived at home than in any other place; and most had frequent contact with parents and relatives. No difference was found in the amount of alcohol and drugs (other than prescriptive) used, or in the number of arrests or time served in jail.

Conclusions based on these results must be considered as tentative, but several trends emerge. First, the LD sample seemed to be adjusting as well as the non-LD sample in a number of important areas (e.g., getting and maintaining employment, having friends). Second, in terms of "quality of life," LD young adults reported that they were significantly less satisfied with their employment situation, as well as their contacts with parents and relatives. They were also less involved in recreational and social activities. Few had goals for further education or training.

In their study of the adult adjustment of persons identified as LD during their school career, Vetter et al. (in prep.) found that LD adults considered daily living skills less important than did non-LD adults. They also found that LD adults were less satisfied with their dating patterns, less likely to generate future goals, and more likely to describe themselves in positive terms, as compared to the non-LD group. No differences were noted, however, between the two groups of adults in the way they judged importance of knowledge of basic academic skills, career-vocational perceptions, and social interactions. In contrast to the results of Lehtinen and Tuomisto (1977), White et al. (1980), and Deshler 
(1978b), Vetter et al., found no difference in the proportion of LD adults reporting dissatisfaction with their current jobs.

\section{Educational Implications}

Based on the presence of learning disabilities among adult populations and the relationship between prevalence and setting, one may expect to find a greater proportion of LD persons in settings such as the Job Corps than in four-year colleges and universities. Also, LD persons represent the lowest academically functioning persons among those of near average, a verage, and above average conceptual ability.

Adults who had been classified as LD while attending secondary school appear to have a lower quality-of-life standard than their age peers. The LD adults are less satisfied with both their social interactions and occupations. They also are neither setting long-range goals nor planning their activities beyond a "day-to-day" basis.

In addition to the findings reported here, the following paradox is documented in secondary LD students. Although LD persons are neither perceived (Skrtic, 1980) nor observed (Schumaker, Sheldon-Wildgen, \& Sherman, 1980; Banikowski \& Alley, 1981) to be dramatically different in social interactions than their nonhandicapped age peers, their self-perception tends to reveal a dramatic difference in this area. Consequently, the need for counseling LD secondary students and LD adults is indicated. Such counseling should involve: (a) career awareness and exploration, (b) problem solving, (c) reality checks, and (d) continuing education.

The most appropriate setting for counseling and the activities that must be integrated into the program may be an area community college, which can offer the LD young adult both vocational and academic options. Other settings include: area vocational technical schools, state job centers, Armed Forces, Job Corps, Adult Basic Education Centers, private and state colleges and universities. Because of its history of coordinating services for other disabled adults, the agency most appropriate to coordinate programming for the LD young adults is the Rehabilitation Services Agency (RSA). Finally, one of the most appropriate professionals for serving the LD young adult's needs may be the vocational rehabilitation counselor.

\section{CONCLUSIONS}

Traditionally, for most LD students, attention has been focused on factors related directly to their academic success in a resource room setting. Issues such as what to teach and how to teach LD students have received primary research and program development attention. These considerations are important for the LD individual's success, but they are not sufficiently powerful to ensure integration of the LD individual into the mainstreamed curriculum or the world of work.

Perhaps the critical index of any intervention's success is the degree to which the targeted skill is generalized across conditions and mainstreamed over time. This index of success is extremely important for older LD students, who are expected to compete in a diverse and demanding set of environments.

Many practitioners and researchers who have studied learning disorders in older populations have stressed the concomitant social interaction difficulties that often beset these individuals. These problems are potentially more of a hindrance to success and adjustment in life than is the mastery of certain academic concepts. Our research suggests that some LD adolescents have problems in social interactions. Since similar social skill deficits are found in other low-achieving adolescent populations as well, LD professionals face difficult decisions regarding the format, agent, and location of any social skill intervention efforts.

Finally, the KU-IRLD has conceptualized learning disabilities as a condition that is not specific to an age group or to the school setting. Individuals with learning disabilities continue to experience difficulty in the secondary school setting and beyond - in employment, training, military settings, and in life adjustment in general. Although our understanding of older LD individuals and the settings in which they must function is growing, it is not yet complete.

The challenge of understanding the learner characteristics, setting demands, and the interaction between these in an attempt to address the needs of older-aged LD individuals is great. Like most other problems in the field of learning disabilities, gaining resolution on the major problems facing $\mathrm{LD}$ adolescents and young adults demands the very best thinking and leadership for meaningful solutions.

\section{REFERENCES}

Alley, G. R., Brownlee, J. E., Deshler, D. D., \& White, W. J. Identification and intervention procedures for the learning disabled in the Earle C. Clements Job Corps Centers: Final report. Submitted to the Singer Corporation and the Department of Labor, April, 1982.

Alley, G. R., Deshler, D. D., \& Warner, M. M. Bayesian screening procedure for identification of learning disabled adolescents: Administration, scoring, and interpretation (Research Monograph 
No. 10). Lawrence, KS: University of Kansas Institute for Research in Learning Disabilities, 1982.

Alley, G. R., Schumaker, J. B., Denton, P., Warner, M. M., \& Deshler, D. D. Paraphrasing: A learning strategy for understanding written material (Research report). Lawrence, KS: University of Kansas Institute for Research in Learning Disabilities, in preparation.

Banikowski, A. K., \& Alley, G. R. The verbal cognitive/socialization strategies used by learning disabled and non-learning disabled junior high school adolescents in peer-to-peer interview situations (Research Report). Lawrence, KS: University of Kansas Institute for Research in Learning Disabilities, 1981.

Blalock, J. W. Persistent problems and concerns of young adults with learning disabilities. In W. M. Cruickshank \& A. A. Silver (Eds.), Bridges to tomorrow, Vol. 2: The best of ACLD. Syracuse, NY: Syracuse University, Press, 1981.

Bruininks, V. L. Actual and perceived peer status of learning-disabled students in mainstream programs. Journal of Special Education, 1978, 12, 51-58.

Bryan, T. S. Peer popularity of learning disabled children. Journal of Learning Disabilities, 1974, 7, 621-625.

Bryan, T. S. Peer popularity of learning disabled children: A replication. Journal of Learning Disabilities, 1976, 9, 307-311.

Bryan, T. S. Social relationships and verbal interactions of learning disabled children. Journal of Learning Disabilities, 1978, 11, 107-115.

Bryan, T. S., \& Wheeler, R. Perception of children with learning disabilities: The eye of the observer. Journal of Learning Disabilities, 1972, 5, 484-488.

Clark, F. L., Warner, M. M., Alley, G. R., Deshler, D. D., Schumaker, J. B., Vetter, A. F., \& Nolan, S. M. Visual imagery and selfquestioning: Strategies to improve comprehension of written material (Research Report No. 51). Lawrence, KS: University of Kansas Institute for Research in Learning Disabilities, 1981.

Crandall, V. C., Katkovsky, W., \& Crandall, V. J. Children's beliefs in their own control of reinforcements in intellectual-academic achievement situations. Child Development, 1965, 36, 91-109.

Deshler, D. D. Issues related to the education of learning disabled adolescents. Learning Disability Quarterly, 1978, I(4), 2-10.(a)

Deshler, D. D. Psychoeducational aspects of learning disabled adolescents. In L. Mann, L. Goodman, \& J. L. Wiederholt (Eds.), Teaching the learning disabled adolescent. Boston: Houghton Mifflin, 1978.(b)

Deshler, D. D., Alley, G. R., Warner, M. M., \& Schumaker, J. B. Instructional practices that promote acquisition and generalization of skills by learning disabled adolescents (Research Monograph No. 4). Lawrence, KS: University of Kansas Institute for Research in Learning Disabilities, 1981.

Deshler, D. D., Schumaker, J. B., Alley, G. R., Warner, M. M., \& Clark, F. L. Learning disabilities in adolescent and adult populations: Research implications. Focus on Exceptional Children, 1982, 15(1), 1-12.

Deshler, D. D., Schumaker, J. B., Alley, G. R., Warner, M. M., \& Clark, F. L. Social interaction deficits in learning disabled adolescents - Another myth? In W. M. Cruickshank \& A. A. Silver (Eds.), Bridges to tomorrow, Vol. 2, The best of ACLD. Syracuse, NY: Syracuse University Press, 1981.

Deshler, D. D., Warner, M. M., Schumaker, J. B., \& Alley, G. R. The learning strategies intervention model: Key components and current status. In J. D. McKinney \& L. Feagams (Eds.), Current topics in learning disabilities. New York: Ahlex Publishing, in press.

Foster, C., Dennis, C., \& Maxwell, J. Teaching self-control procedures to learning disabled youths (Research Report No. 47). Lawrence, KS: University of Kansas Institute for Research in Learning Disabilities, 1981.

Gorney-Krupsaw, B., Atwater, J., Powell, L., \& Morris, E. K. Improving social interactions between learning disabled adolescents and teachers: $A$ child effects approach (Research Report No. 45). Lawrence, KS: University of Kansas Institute for Research in Learning Disabilities, 1981.
Hallahan, D. P., Gajor, A. H., Cohen, S. B., \& Tarver, S. G. Selective attention and locus of control in learning disabled and normal children. Journal of Learning Disabilities, 1978, 11, 231-236.

Hardy, M. I. Disabled readers: What happens to them after elementary school? Canadian Education \& Research Digest, 1968, 8, 338-346.

Haring, N., \& Bateman, B. Teaching the learning disabled child. Englewood Cliffs, NJ: Prentice-Hall, 1977.

Harnden, G. M., Alley, G. R., \& Deshler, D. D. Incidence of learning disabilities among military personnel (Research Report in preparation). Lawrence, KS: University of Kansas Institute for Research in Learning Disabilities, in preparation.

Harnden, G. M., Meyen, E. L., Alley, G. R., \& Deshler, D. D. Performance of learning disabled high-school students on the Armed Services Vocational Aptitude Battery (Research Report No. 24). Lawrence, KS: University of Kansas Institute for Research in Learning Disabilities, 1980.

Hazel, J. S., Schumaker, J. B., \& Sheldon-Wildgen, J. Application of a social skill and problem-solving group training program to learning disabled and non-learning disabled youth (Research Report No. 30). Lawrence, KS: University of Kansas Institute for Research in Learning Disabilities, 1981.

Hazel, J. S., Schumaker, J. B., Sherman, J. A., \& Sheldon-Wildgen, J. ASSET: A social skills program for adolescents. Champaign, IL: Research Press, 1981.

Henker, B., Whalen, C. K., \& Hinshaw, S. P. The attributional contexts of cognitive intervention strategies. Exceptional Education Quarterly, 1980, 1, 17-30.

Kirk, S. A., Kliebhan, J., \& Lerner, J. Teaching reading to slow and disabled readers. Boston: Houghton Mifflin, 1978.

Lehtinen, H., \& Tuomisto, J. On the construction and application of an activation variable in the planning of adult education systems. Adult Education in Finland, 1977, 13, 3-30.

Lenz, B. K., Deshler, D. D., Alley, G. R., Schumaker, J. B., \& Warner, M. M. A word identification strategy for pronouncing unfamiliar words (Research Report). Lawrence, KS: University of Kansas Institute for Research in Learning Disabilities, in preparation.

Marsh, G., Gearheart, C. K., \& Gearheart, B. R. The learning disabled adolescent: Program alternatives in the secondary school. St. Louis: C. V. Mosby Co., 1978.

Mathews, R. M., Whang, P., \& Fawcett, S. B. Behavioral assessment of job-related skills: Implications for learning disabled young adults (Research Report No. 6). Lawrence, KS: University of Kansas Institute for Research in Learning Disabilities, 1980.

Mehring, T., \& Alley, G. R. The interaction of selected aptitude and cognitive style measures with a learning strategies intervention used to teach self-questioning to junior high school learning disabled students (Research Report in preparation). Lawrence, KS: University of Kansas Institute for Research in Learning Disabilities, in prep.

Mellard, D. F., \& Alley, G. R. Production deficiency vs. processing dysfunction: An experimental assessment of $L D$ adolescents (Research Report No. 40). Lawrence, KS: University of Kansas Institute for Research in Learning Disabilities, 1981.

Moran, M. R., Schumaker, J. B., \& Vetter, A. F. Teaching a paragraph organization strategy to learning disabled adolescents (Research Report No. 54). Lawrence, KS: University of Kansas Institute for Research in Learning Disabilities, 1981.

O'Leary, S. G., \& Dubey, D. R. Applications of self-control procedures by children: A review. Journal of Applied Behavior Analysis, 1979, I2, 449-467.

Pearl, R., Bryan, T., \& Donahue, M. Learning disabled children's attributions for success and failure. Learning Disability Quarterly, $1980,3,3-9$

Raven, J. Advanced Progressive Matrices: Sets I and II. New York: Psychological Corp., 1956.

Schmidt, J., Deshler, D. D., Alley, G. R., \& Schumaker, J. B. Teaching methodologies for enhancing generalization in learning disabled adolescents (Research Report). Lawrence, KS: University 
of Kansas Institute for Research in Learning Disabilities, in preparation.

Schumaker, J. B., Deshler, D. D., Denton, P., Alley, G. R., Clark, F. L., \& Warner, M. M. Multipass: A learning strategy for improving reading comprehension (Research Report No. 33). Lawrence, KS: University of Kansas Institute for Research in Learning Disabilities, 1981.

Schumaker, J. B., \& Ellis, E. S. Social skills training with learning disabled adolescents: A generalization study (Research Report No. 65). Lawrence, KS: University of Kansas Institute for Research in Learning Disabilities, 1982.

Schumaker, J. B., Hazel, J. B., Sherman, J. A., \& Sheldon, J. Social skill performances of learning disabled, non-learning disabled, and delinquent adolescents (Research Report No. 60). Lawrence, KS: University of Kansas Institute for Research in Learning Disabilities, 1982.

Schumaker, J. B., Sheldon-Wildgen, J., \& Sherman, J. A. $A n$ observational study of the academic and social behaviors of learning disabled adolescents in the regular classroom (Research Report No. 22). Lawrence, KS: University of Kansas Institute for Research in Learning Disabilities, 1980.

Schumaker, J. B., Sheldon-Wildgen, J., \& Sherman, J. A. Social interaction of learning disabled junior high students in their regular classroom. Journal of Learning Disabilities, 1982, 15, 355-358.

Schumaker, J. B., Warner, M. M., Deshler, D. D. \& Alley, G. R. An epidemiological study of learning disabled adolescents in secondary schools: Details of the methodology (Research Report No. 12). Lawrence, KS: University of Kansas Institute for Research in Learning Disabilities, 1980.

Schwartz, M., Gilroy, J., \& Lynn, G. Neuropsychological and psychological implications of spelling deficit in adulthood: A case report. Journal of Learning Disabilities, 1976, 9, 144-148.

Seabaugh, G. O., \& Schumaker, J. B. The effects of self-regulation training on the academic productivity of $L D$ and NLD adolescents (Research Report No. 37). Lawrence, KS: University of Kansas Institute for Research in Learning Disabilities, 1981. (a)

Seabaugh, G. O., \& Schumaker, J. B. Effects of three conferencing procedures on the academic productivity of $L D$ and NLD adolescents (Research Report No. 36). Lawrence, KS: University of Kansas Institute for Research in Learning Disabilities, 1981. (b)

Siegel, E. The exceptional child grows up: Guidelines for understanding and helping the brain-injured adolescent and young adult. New York: E. P. Dutton, 1974.

Skrtic, T. M. The regular classroom interactions of learning disabled adolescents and their teachers (Research Report No. 8). Lawrence, KS: University of Kansas Institute for Research in Learning Disabilities, 1980.

Stephens, T. Teaching skills to children with learning and behavior disorders. Columbus, OH: Charles Merrill, 1977.

Tollefson, N., Tracy, D. B., Johnsen, E. P., Borgers, S., Buenning, M., Farmer, A., \& Barke, C. An application of attribution theory to developing self-esteem in learning disabled adolescents (Research Report No. 23). Lawrence, KS: University of Kansas Institute for Research in Learning Disabilities, 1980.

Tollefson, N., Tracy, D. B., Johnsen, E. P., Buenning, M., \& Farmer, A. Implementing goal setting activities with $L D$ adolescents (Research Report No. 48). Lawrence, KS: University of Kansas Institute for Research in Learning Disabilities, 1981.

Vetter, A. A., Deshler, D. D., Schumaker, J. B., Warner, M. M., \& Alley, G. R. Post-secondary follow-up study of a group of learning disabled and low achieving young adults (Research Report). Lawrence, KS: University of Kansas Institute for Research in Learning Disabilities, in preparation.

Whang, P. L., Fawcett, S. B., \& Mathews, R. M. Teaching job-related social skills to learning disabled adolescents (Research Report No. 42). Lawrence, KS: University of Kansas Institute for Research in Learning Disabilities, 1981.

White, W. J., Schumaker, J. B., Warner, M. M., Alley, G. R., \& Deshler, D. D. The current status of young adults identified as learning disabled during their school career (Research Report No. 21). Lawrence, KS: University of Kansas Institute for Research in Learning Disabilities, 1980.

Wiederholt, J. L. Educating the learning disabled adolescent: Some assumptions. Learning Disability Quarterly, 1978, 1(4), 11-23.

Wong, B. Motivation for learning in mildly handicapped adolescents and young adults: A review of related theories. Exceptional Education Quarterly, 1980, 1(2), 37-45.

Woodcock, R. W., \& Johnson, M. B. Woodcock-Johnson psychoeducational battery. Boston: Teaching Resources Corp., 1977.

Preparation of this manuscript was supported by Contract \#300-77-0494 with the Office of Special Education and Rehabilitation, U.S. Office of Education, through Title VI-G of Public Law 91-230.

The authors of this article wish to acknowledge the instrumental role that Dr. Edward L. Meyen and Dr. Richard Schiefelbusch have played in the KU-IRLD. Their leadership and direction during the early years of the Institute were instrumental in setting a pattern for our overall efforts. Dr. Meyen is Associate Vice Chancellor of Research and Development and Dr. Schiefelbusch is Director of the Bureau of Child Research at the University of Kansas.

Information on obtaining research reports from the $K U-I R L D$ can be obtained by writing to Donald $D$. Deshler, University of Kansas Institute for Research in Learning Disabilities, 313 Carruth-O'Leary Hall, Lawrence, $K S 66045$.

\section{CLASSROOM FORUM}

\author{
Beverly Dexter \\ Lynchburg College
}

Several of my students will be mainstreamed into regular classrooms at the beginning of the coming school year. Do you have any suggestions on how I can convey to their teachers the fears and concerns these students have?

After talking with many students and teachers about their feelings concerning "graduation" from self-contained special to regular classrooms with resource help, I decided to make a composite tape of these concerns. All of the students, regardless of their ages, revealed similar patterns of needs and fears. At that point I realized that 
perhaps a letter format might be used to condense and summarize the students' feelings and help convey these to the teachers. The following letter is the result.

\section{JUST LET ME BE ME!}

\section{An Open Letter to the Classroom Teacher}

\section{Dear Teach,}

Well, here it is the beginning of a new school year. I thought for sure I'd be in Miss Black's room again this year. After all, I've been in there for the past two years. When they told me I would have you as my fourth grade teacher, I thought I'd been promoted. But then Miss Black told me that I'd been mainstreamed, whatever that means. The best I can tell is that I'll be in your class most of the day, but from 9-10 a.m. I'll be with Miss Black again back in my old classroom. Maybe I'll see some of my old friends in there. I sure hope so, because I don't know very many kids in this new classroom. Are you going to introduce me, or will I have to meet these kids all by myself?

You know, I'm not the greatest at making new friends. When I was in Miss Black's class, I didn't have to worry too much about that. She always made sure that each one of us had a special friend in the classroom who could help us whenever we got stuck with a problem in our work. Mary helped me a lot in my math, and I helped Randy with his science.

She also had these neat learning centers set up in her room where we could go with our "buddy" to work on special projects. We had to take turns using the centers, but this helped us learn to share. Of course, we did have a few kids who didn't always want to share, but nobody's perfect. And Miss Black always posted a chart for us so we knew which center we were supposed to go to and who our buddy would be for that day. Sometimes we even had the same buddy for a whole week!

Miss Black had a way of knowing which two kids could work best together for certain projects, so she would help us make up our minds about who we wanted as our partners. I'm glad she did this because nobody ever felt left out. It was up to us to try to work well with our partners because we were supposed to be a team, and she always said that teams do best when everybody pitches in to help.

She also said that the most important thing we could do was to try. She always praised us for trying, whether we got all the answers right or not. Sometimes I'd try very hard to get all the answers right on my math paper, but I'd still miss a few. She didn't get mad at me for missing those problems, though. Instead, she got excited over all the ones I did right. That made me feel so good that I'd try to do even better on the next paper.

Maybe you've already talked to Miss Black about this, but I think I'd better warn you that I don't write or read too good. When I do use my best handwriting, it seems to take me forever to do the assignment. So sometimes I go too fast and just forget about how pretty and neat the paper is supposed to be. Miss Black says if she can't read it, she won't know if I did it right or not, so I have been known to scribble when I wasn't sure of the answer. Besides, we worked so much on printing both times I was in first grade that by the time we got to cursive I was sick of the whole thing. Why don't they make up their minds? I just about had the manuscript letters figured out when Miss Black told me I was ready for cursive.

For a while there I thought I had the whole thing figured out. If I did well in the manuscript, it meant I would be punished by having to learn cursive. But Miss Black caught on to my tricks and set me straight. She showed me how the older kids were using cursive because they were already good at using manuscript. She said it was a stepping stone to being ready for a regular classroom. Instead of being punishment, it was a reward for doing something else very well. I really like the way she made me feel so grown up for agreeing to try cursive. And you know what? Once I tried it, I liked it. You don't have to stop after every letter, and that sure makes it go faster for me. But I still go too fast sometimes and get a little careless. If you'll give me enough time to do my work, I'll try not to scribble.

Now, about this reading ... That's what got me into Miss Black's class in the first place. In the first grade I never could remember which squiggles were which. My teacher kept telling me that some of the squiggles said their name. But I never heard a squiggle talk, no matter how long I sat there with my reading book open waiting for a squiggle to say anything, let alone its name. The teacher used to really get mad at me when I didn't see that a word like "baby" had the same beginning squiggle as my name, "Billy." I couldn't write my name then, so I didn't know this. Now I know that a little $b$ is a lot different from a capital one. Besides, the teacher had her teacher's manual right there in front of her, and all I had was my reading book. No wonder she always knew the answers!

Another thing you might want to know about me is that although you seem like a nice teacher, I'm not sure whether I can trust you yet. You see, I spent two years in first grade before going to Miss Black's room. 
The first year in first grade was bad, and the second year was terrible. Do you know how it feels to be in the same grade for two years in a row? Your friends laugh at you, and it seems like the harder you try, the worse things get. I didn't learn much from that dumb reading series the first year, and when I saw those same books again, I wanted to scream. We had drilled and drilled and drilled on those words and I still couldn't remember them.

Then, when I went to Miss Black's room, I thought she'd pull out those same books again. I was going to run away if she did, so it's a good thing she had different ones. She even used a different way to teach me how to read. First she told me the word, then she had me copy it on a card. I would practice saying the word and spelling it while I traced over the letters with my finger. She even had me write it in the air for extra practice when I got good at tracing it on the card. I learned a lot of words that first year with her, and we kept them in my very own Word Box.

Some of the kids didn't need to trace the letters the way I did, though. Ralph and Steve used a tape recorder for their reading. At first they would listen to the story on the tape while they followed it in their books. Then they would read right along with the tape. When they got really good, Miss Black would let them tape themselves reading stories, and she would listen to the tapes with them when they were finished. I got to do this a couple of times, and I really liked it because I could do this all by myself at one of the learning centers.

She used a lot of other things for teaching us how to read, do math, and write, but I can't remember them all now. I know if you would just talk to her, she could tell you about them. And I'll bet you have some neat ideas to share with her, too. Like that bulletin board you have up now that you said we could work on this afternoon. You put up the border for it, but you said we'd do the rest of it. What did you call it - The Big Think Machine? We're each supposed to make up a question for the machine to answer about the science experiment we did this morning. Tomorrow we'll get into small groups to work on the answers before we put them up on the bulletin board.

Y'know, Teach, I don't think this is going to be so bad after all. Just let me be me, and I promise I'll try my best.

\section{INDEX • VOLUME 15}

\section{Author Index}

Alberto, Paul A. (March 1983)

Alley, Gordon R. (Sept. 1982; May 1983)

Bos, Candace S. (Jan. 1983)

Briggs, Thomas (March 1983)

Clark, Frances L. (Sept. 1982; May 1983)

Deshler, Donald D. (Sept. 1982; May 1983)

Dexter, Beverly (Dec. 1982; March, May 1983)

Garrett, Elizabeth (March 1983)

Glass, Gene V (Dec. 1982)

Harris, Karen R. (Oct. 1982)

Harth, Robert (Nov. 1982)

Katz, Elinor Lipit (Feb. 1983)

Kavale, Kenneth A. (Dec. 1982)

Kroth, Roger (April 1983)

Lund, Kathryn A. (Jan. 1983)

McCarthy, Jeanne M. (Jan. 1983)

Otteni, Harriet (April 1983)

Schumaker, Jean B. (Sept. 1982; May 1983)

Umberger, Forrest (March 1983)

Warner, Michael M. (Sept. 1982; May 1983)

\section{Chronological Index of Titles}

Learning Disabilities in Adolescent and Young Adult Populations: Research Implications (Sept. 1982)

Cognitive-Behavior Modification: Application With Exceptional Students (Oct. 1982)

The Feurstein Perspective On the Modification of Cognitive Performance (Nov. 1982)

The Efficacy of Special Education Interventions and Practices: A Compendium of MetaAnalysis Findings (Dec. 1982)

Assessment of Young Children with Special Needs (Jan. 1983)

Microcomputers: A Course of Study for Gifted Students (Feb. 1983)

Selection and Initiation of a Nonvocal Communication Program for Severely Handicapped Students (March 1983)

Parent Education Programs That Work: A Model (April 1983)

Learning Disabilities in Adolescent and Adult Populations: Research Implications (Part II) (May 1983)

CLASSROOM FORUM (Dec. 1982; March, May 1983) 